\title{
Qat-induced intestinal obstruction: A case series of a new entity
}

\author{
Mhd Firas Safadi $1^{1,2}$
}

${ }^{1}$ Department of Surgery, Yemeni-Egyptian Hospital, Sanaa, Yemen, ${ }^{2}$ Department of General, Visceral, and Thoracic Surgery, Klinikum Darmstadt, Darmstadt, Germany

\begin{tabular}{|c|}
\hline Access this article online \\
\hline Website: www.avicennajmed.com \\
\hline DOI: 10.4103/ajm.AJM_198_17 \\
\hline Quick Response Code: \\
\hline
\end{tabular}

\begin{abstract}
Background: Qat-induced intestinal obstruction is an acute manifestation of qat chewing which was not described previously in the literature. The aim of this case series is to describe the clinical presentation, the diagnostic and therapeutic measures, and the course of the disease. Methods: This retrospective case series included all patients who presented with qat-induced intestinal obstruction between July 1, 2013, and December 31, 2015. Results: The study included seven patients (five males and two females). The mean age was 41.4 years (22-60 years). All patients presented after 8-12 h of prolonged qat chewing with abdominal pain, severe abdominal distension, and inability to pass stool. Laboratory results were normal apart from slight leukocytosis $\left(<15 \times 10^{\%} / L\right)$ in three patients. All patients showed air-fluid levels on the erect abdominal $X$-ray. The management included intravenous fluids and symptomatic therapy. The symptoms resolved in 1-2 days and the follow-up after 1 week showed no residual complaints. Conclusions: Qat-induced intestinal obstruction is associated with the heavy and prolonged consumption of qat. The presentation mimics acute intestinal obstruction, but the course is benign. Spontaneous resolution with supportive inpatient treatment is the rule.
\end{abstract}

Key words: Intestinal obstruction, khat, mechanical ileus, paralytic ileus, qat

\section{INTRODUCTION}

Qat is a stimulating plant which is consumed in Yemen and other countries around the horn of Africa. The green leaves are chewed and packed under the cheek for several hours. The various health consequences of qat chewing in many organ systems were extensively discussed in the literature. ${ }^{[1]}$

Chronic constipation is one of the most common gastrointestinal manifestations of qat consumption. ${ }^{[2]}$ However, I noticed during my work in Yemen that some patients presented with a typical clinical picture of acute intestinal obstruction after prolonged qat sessions. This complication of qat chewing was not described previously in the literature.

In this retrospective case series, I report seven cases of qat-induced intestinal obstruction as a new clinical condition.

Address for correspondence: Dr. Mhd Firas Safadi, Department of General, Visceral, and Thoracic Surgery, Klinikum Darmstadt, Grafenstraße 9, 64293 Darmstadt, Germany. E-mail: doctor.safadi@gmail.com
I represent the clinical characteristics of the patients and describe the course of the disease. Finally, I suggest possible explanations for the etiology and pathophysiology of this entity.

\section{METHODS}

This case series included all patients who presented to the emergency department of a local hospital in Yemen between July 1, 2013, and December 31, 2015, and were retrospectively diagnosed as having qat-induced intestinal obstruction.

The inclusion criteria included the occurrence of clinical symptoms and signs of intestinal obstruction after several

This is an open access journal, and articles are distributed under the terms of the Creative Commons Attribution-NonCommercial-ShareAlike 4.0 License, which allows others to remix, tweak, and build upon the work non-commercially, as long as appropriate credit is given and the new creations are licensed under the identical terms.

For reprints contact: reprints@ medknow.com

Cite this article as: Safadi MF. Qat-induced intestinal obstruction: A case series of a new entity. Avicenna J Med 2018;8:82-6. 
hours of qat chewing without another explanation of the obstruction. The exclusion criteria included the presence of other possible causes of ileus or a history of previous surgical interventions on the abdomen.

The data were collected retrospectively from the archived files and included clinical, laboratory, and radiological characteristics of the patients. The treatment course and the period of stay in the hospital were documented. All patients were reassessed in the outpatient clinic 1 week after discharge. The patients were not followed in the long term.

\section{RESULTS}

This case series included seven patients. Three other patients were excluded from the analysis due to previous abdominal surgeries, which included an exploratory laparotomy in two men and multiple gynecological surgeries in a woman.

The mean age of the patients was 41.4 years (22-60 years). All patients presented to the emergency department between 6 a.m. and 12 p.m. because of complaints that appeared after 8-12 h of prolonged qat chewing on the previous night. Symptoms included crampy abdominal pain, severe distension and bloating, anorexia, nausea, and inability to pass stool. Vomiting occurred in five patients, and three patients could not pass flatus. Table 1 summarizes the clinical characteristics of the patients.

The approach included detailed history taking, clinical examination, laboratory tests, and imaging studies. All patients were previously fit, were taking no medications, had no history of abdominal surgeries, and experienced no such symptoms apart from chronic constipation. Clinical examination showed normal vital signs with no fever. Abdominal examination revealed severe distension and diffuse tenderness without peritoneal signs. The intestinal sounds were present and showed moderate activity. Rectal examination showed traces of stool.

\begin{tabular}{|c|c|c|c|c|c|c|c|}
\hline \multicolumn{8}{|c|}{$\begin{array}{l}\text { Table I: General characteristics of the patients in this } \\
\text { series }\end{array}$} \\
\hline ID & $\begin{array}{c}\text { Age } \\
\text { (years) }\end{array}$ & Gender & Vomiting & Flatus & Stool & Leukocytosis & $\begin{array}{c}\text { Stay } \\
\text { (days)* }\end{array}$ \\
\hline I & 30 & Female & - & + & - & - & I \\
\hline 2 & 22 & Male & + & - & - & - & I \\
\hline 3 & 53 & Male & + & + & - & - & I \\
\hline 4 & 60 & Male & + & - & - & + & 2 \\
\hline 5 & 55 & Female & + & - & - & + & 2 \\
\hline 6 & 35 & Male & + & + & - & - & I \\
\hline 7 & 35 & Male & - & + & - & + & I \\
\hline
\end{tabular}

Initial laboratory tests showed slight leukocytosis $\left(<15 \times 10^{9} / \mathrm{L}\right)$ in three patients. All other tests were in the normal range. Erect abdominal X-ray showed air-fluid levels, which was typical for intestinal obstruction [Figure 1]. All patients underwent abdominal ultrasound and abdominal computed tomography scan with oral and intravenous contrast, which showed dilated bowel loops, air-fluid levels, and intraluminal densities with mottled gas pattern.

All patients were admitted for inpatient observation and management. A nasogastric tube was passed, and it produced a viscous grassy green output. The patients were allowed to take sips of water per os. The daily need of fluids was administered intravenously. Medications were administered intravenously and included a proton pump inhibitor, metoclopramide, and acetaminophen. All patients received also rectal enemas twice daily.

The patients were followed with serial clinical examination and control of erect abdominal X-ray and laboratory tests on the next morning. All patients showed rapid clinical improvement within hours of admission. The nasogastric tube was removed upon resolution of abdominal pain, and normal diet was resumed over hours. The patients exhibited 3-5 episodes of copious defecation with rapid resolution of symptoms. Five patients could be discharged on the next morning with complete resolution of all symptoms and normal follow-up tests. The other two patients stayed for an additional day because of slight residual pain and bloating, which resolved completely on the next morning.

All patients were well in the follow-up visit 1 week after discharge, and no patient presented again for the recurrence of symptoms within the study period.

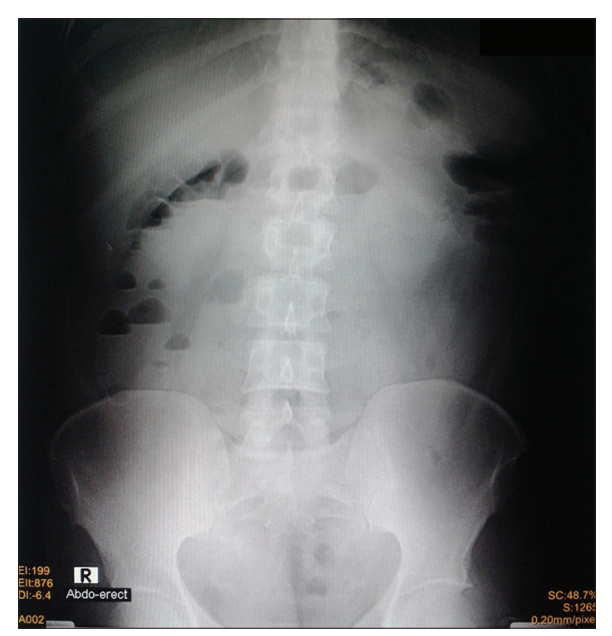

Figure 1: Erect abdominal X-ray of a patient in this series. Air-fluid levels can be seen in the upper abdomen with scarce abdominal gas in the lower abdomen. It may be difficult to distinguish these findings from mechanical bowel obstruction 


\section{DISCUSSION}

Qat-induced intestinal obstruction is an acute entity caused by extensive and prolonged qat chewing. Presentation and radiological findings can imitate mechanical bowel obstruction. Rapid resolution with inpatient conservative therapy is the rule. This entity was not described previously in the literature.

Catha edulis, widely known as qat (also spelled kat or khat), is a stimulating plant that is planted and consumed in Yemen among other nearby countries [Figure 2]. Concomitant smoking and intake of other soft drinks, such as soda and power drinks, are typical. This practice is called "Takhzeen," meaning "storing" in the local Arabic language.

\section{General effects of qait}

The main effective compounds in qat are the two alkaloids, cathinone ( $\beta$-ketoamphetamine) and cathine (d-norpseudoephedrine). These natural alkaloids belong to the amphetamine family, and they have similar, albeit weaker, effects on the central nervous system. ${ }^{[3]}$ The stimulating effects of qat include enhanced level of mental performance, euphoria, and improved self-esteem. The prolonged intake induces a mild-to-severe psychological dependence. Withdrawal causes mild short-lived symptoms of dullness and depression. ${ }^{[4]}$

Qat was heavily studied for its negative effects on teeth and mouth hygiene. The prolonged use can also lead to cardiovascular disease, cytotoxic effects on the liver and kidney, and mental illness and psychosis. ${ }^{[1]}$ The economic burden of qat consumption is also substantial, as some Yemeni citizens waste more than $50 \%$ of their income on qat. Because of worldwide smuggling, qat consumption can

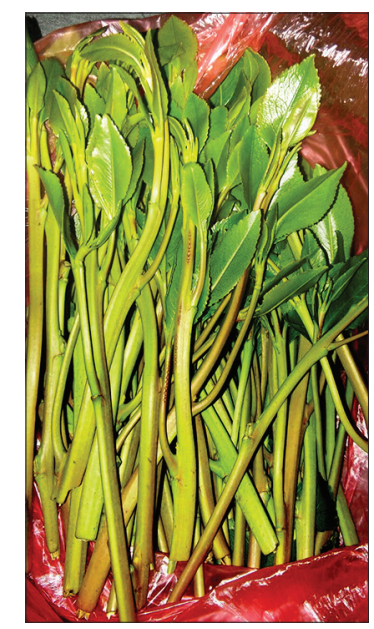

Figure 2: The shiny leaves of the qat plant are prepared by rinsing and cleansing before they are left to dry. The leaves are picked out from the thick branches, chewed well, and packed under the cheek for hours be encountered in the developed countries. Therefore, every practitioner in regions of cultural diversity should be aware of qat consumption and its potential consequences.

\section{Gastrointestinal effects of qat}

The logistic regression analysis performed by Nigussie et al. showed that gastrointestinal disorders are more common among qat chewers. ${ }^{[2]}$ Documented gastrointestinal effects of qat include reduced appetite, malnutrition, chronic esophagitis and gastritis, duodenal ulcer, constipation, and hemorrhoids. ${ }^{[1,5,6]}$

Chronic constipation is the most common gastrointestinal symptom of qat consumption. It was found to affect $15 \%-18.4 \%$ of users in a survey of the World Bank in Yemen, ${ }^{[5]} 23.4 \%$ of 1019 university students in a survey in Ethiopia, ${ }^{[2]}$ and up to $80.8 \%$ of 424 college students in another recent study in Ethiopia. ${ }^{[7]}$ I quote an interesting fact about the relationship between qat and chronic constipation from an article that was published by Halbach in 1972: "... when a ban was imposed on khat in Aden in 1957 the sales of laxatives decreased by $90 \%$ but returned to the original level soon after the ban was lifted." ${ }^{[8]}$

However, all these studies described constipation as a chronic entity among regular qat consumers, and no report hitherto described the occurrence of the characteristic clinical and radiological features of acute bowel obstruction after heavy consumption.

\section{Suggested mechanisms of intestinal obstruction}

I suggest two mechanisms as an etiology of qat-induced intestinal obstruction: mechanical and toxic. As illustrated in Figure 3, it seems that the constellation of symptoms develop when both mechanisms act simultaneously.

The large load of swallowed fibers can cause a subtotal mechanical obstruction. The presence of vomiting in most patients in this series and the output of a large amount of viscous fluids through the nasogastric tube over hours support the theory of a mechanical barrier. Although the chewed qat leaves are stored in the mouth and not swallowed intentionally, the chopped particles are in fact continuously swallowed during the prolonged sessions, which can last several hours. This is accompanied by the intake of large amounts of varied drinks, which carries additional chewed particles downstream. The net result is a bezoar effect with a large quantity of obstructing indigestible fibers, which partially block the gastrointestinal passage.

On the other hand, the toxic mechanism is mainly attributed to the pharmacological effects of cathinone 


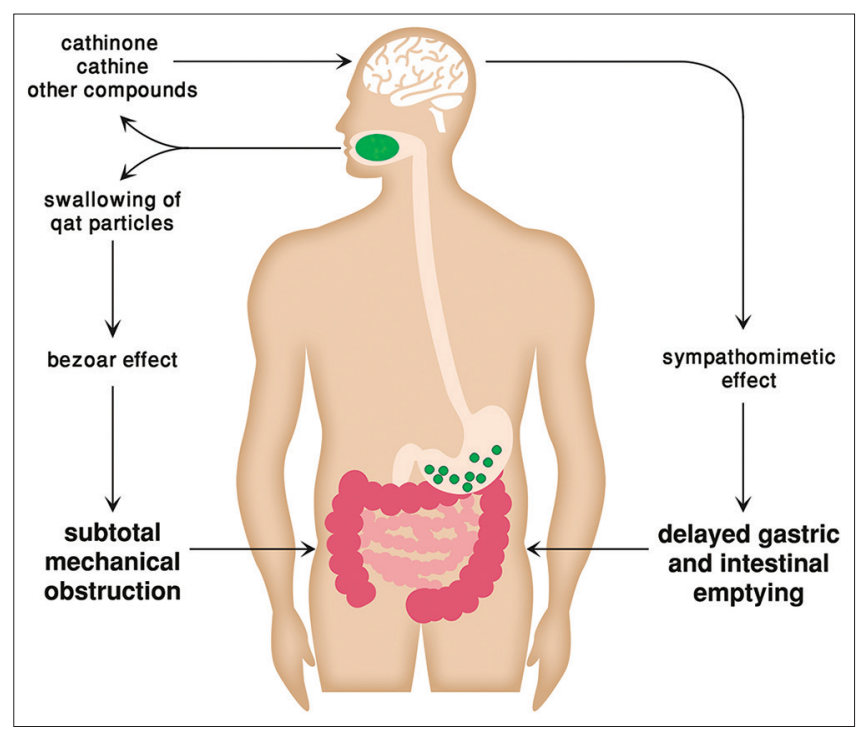

Figure 3: Possible mechanisms of qat-induced intestinal obstruction. The delayed transit through the gastrointestinal tract is induced by the toxic effects of qat. When accompanied by extensive swallowing of qat particles, the mechanical block leads to a syndrome of subtotal mechanical obstruction

and cathine. These alkaloids induce a sympathomimetic response in the gastrointestinal tract, both directly (when metabolized to norephedrine and norpseudoephedrine) and indirectly (through the stimulation of the central nervous system). This results in an inhibitory gastrointestinal effect with smooth muscle relaxation and delayed intestinal transit time. ${ }^{[9,10]}$ It was also demonstrated that severe constipation episodes can be relieved by parasympathomimetics such as physostigmine, although no such treatment was applied on the patients in this series. ${ }^{[8]}$

Several previous pharmacological studies have documented the effects of qat on both gastric and intestinal motility. An interesting work of Heymann et al. using radiolabeled semisolid meal showed that chewing of qat in comparison with lettuce causes a statistically significant delay in gastric emptying $(P<0.02){ }^{[11]}$ The pharmacodynamic study in another controlled trial by Widler et al. showed that cathinone attained maximal plasma concentration after $127 \pm 30 \mathrm{~min}$, and the terminal elimination half-life equaled $260 \pm 102 \mathrm{~min} .{ }^{[12]}$ This time range corresponds well with the onset of symptoms and clinical course in the patients of this series as summarized in Table 2.

Therefore, the overall pathophysiology of the disorder can be expressed as paralytic ileus combined with subtotal mechanical obstruction, without a clinical picture of a pure ileus or a typical mechanical obstruction with an obvious transitional point. It is also worth mentioning that three other patients, who were excluded because of previous abdominal surgeries, presented with the same clinical spectrum after qat

\begin{tabular}{|c|c|}
\hline Time frame & Clinical course \\
\hline Around midnight & $\begin{array}{l}\text { Extensive chewing of qat leaves with ingestion of } \\
\text { drinks for } 3-6 \mathrm{~h}\end{array}$ \\
\hline 4-6 $\mathrm{h}$ after chewing & Onset of typical symptoms of intestinal obstruction \\
\hline 4-6 $\mathrm{h}$ after onset & $\begin{array}{l}\text { Presentation, admission, and initiation of } \\
\text { conservative management }\end{array}$ \\
\hline $\begin{array}{l}24-48 \mathrm{~h} \text { after } \\
\text { admission }\end{array}$ & $\begin{array}{l}\text { Complete resolution of symptoms and discharge } \\
\text { without consequences }\end{array}$ \\
\hline
\end{tabular}

chewing, and conservative measures were also effective in all of them. This may suggest that qat can initiate or aggravate bowel obstruction in patients with potential intestinal adhesions after previous abdominal surgeries, again through both the mechanical and toxic effects.

A question may arise about the triggers of this entity, as these patients are life-long qat consumers. Considering that three patients in the series were older than 50 years of age, it may be difficult to justify why chronic constipation proceeded to clinical bowel obstruction at this particular point. Previous research showed that tolerance to the sympathetic effects of qat my develop over time, which prompts some consumers to increase the taken quantity. ${ }^{[13]}$ This mechanism could be responsible for the acute development of an obstruction syndrome. Other factors may also contribute to the acute presentation such as the sort of qat and the types and quantities of the ingested drinks.

The main drawback of this analysis is the retrospective collection of data. My initial clinical impression on approaching these patients was oriented toward a syndrome of pathological mechanical obstruction. I was only able to recognize the entity after presentation of multiple similar cases in a series over several months. For the same reason, all cases were approached as a usual bowel obstruction without application of other specific diagnostic or therapeutic interventions.

More studies are needed to determine the characteristics of qat-induced intestinal obstruction. Fields of interest include the true incidence among qat chewers, the rate of recurrence, whether the incidence is related to specific premorbidities (such as diabetes or previous gastrointestinal disorders), whether it is really enhanced by silent adhesions after previous surgeries, and whether patients may require more aggressive treatments in extreme cases.

\section{CONCLUSIONS}

Qat-induced intestinal obstruction is an acute manifestation of qat chewing which was not previously described in the 
literature. The prominent clinical symptoms include severe abdominal pain and distension with inability to pass stool. The erect abdominal X-ray shows air-fluid levels and the laboratory results may show mild leukocytosis. Spontaneous regression is the rule with no need for further treatments other than general conservative management.

\section{Acknowledgments}

I would like to thank Dr. Florian Graupe and Dr. Wasim Maziak for reviewing the text and giving valuable feedback. I would also like to thank Mr. Muhammad Al-Umari for providing the qat photo.

\section{Financial support and sponsorship}

Nil.

\section{Conflicts of interest}

There are no conflicts of interest.

\section{REFERENCES}

1. Wabe NT. Chemistry, pharmacology, and toxicology of khat (Catha edulis forsk): A review. Addict Health 2011;3:137-49.

2. Nigussie T, Gobena T, Mossie A. Association between khat chewing and gastrointestinal disorders: A cross sectional study. Ethiop J Health Sci 2013;23:123-30.
3. Dhaifalah I, Santavý J. Khat habit and its health effect. A natural amphetamine. Biomed Pap Med Fac Univ Palacky Olomouc Czech Repub 2004;148:11-5.

4. El-Setouhy M, Alsanosy RM, Alsharqi A, Ismail AA. Khat dependency and psychophysical symptoms among chewers in Jazan Region, Kingdom of Saudi Arabia. Biomed Res Int 2016;2016:2642506.

5. Yemen Towards Qat Demand Reduction. International Bank for Instruction and Development/World Bank. Contract. 39738-YE; 2007.

6. Kennedy JG, Teague J, Rokaw W, Cooney E. A medical evaluation of the use of qat in North Yemen. Soc Sci Med 1983;17:783-93.

7. Teni FS, Surur AS, Hailemariam A, Aye A, Mitiku G, Gurmu AE, et al. Prevalence, reasons, and perceived effects of khat chewing among students of a college in Gondar town, Northwestern Ethiopia: A Cross-sectional study. Ann Med Health Sci Res 2015;5:454-60.

8. Halbach H. Medical aspects of the chewing of khat leaves. Bull World Health Organ 1972;47:21-9.

9. Toennes SW, Harder S, Schramm M, Niess C, Kauert GF. Pharmacokinetics of cathinone, cathine and norephedrine after the chewing of khat leaves. Br J Clin Pharmacol 2003;56:125-30.

10. Brenneisen R, Geisshüsler S, Schorno X. Metabolism of cathinone to (-)-norephedrine and (-)-norpseudoephedrine. J Pharm Pharmacol 1986;38:298-300.

11. Heymann TD, Bhupulan A, Zureikat NE, Bomanji J, Drinkwater C, Giles $\mathrm{P}$, et al. Khat chewing delays gastric emptying of a semi-solid meal. Aliment Pharmacol Ther 1995;9:81-3.

12. Widler P, Mathys K, Brenneisen R, Kalix P, Fisch HU. Pharmacodynamics and pharmacokinetics of khat: A controlled study. Clin Pharmacol Ther 1994;55:556-62.

13. Nencini P, Ahmed AM, Amiconi G, Elmi AS. Tolerance develops to sympathetic effects of khat in humans. Pharmacology 1984;28:150-4. 